\title{
Lower extremity amputation increases oscillatory flow in the infrarenal aorta: A new potential risk factor for abdominal aortic aneurysm development
}

\author{
Alexander V Smolensky ${ }^{1 *}$, Stephanie Clement-Guinaudeau ${ }^{2}$, Robert W Taylor ${ }^{1}$, John N Oshinski ${ }^{2}$ \\ From 15th Annual SCMR Scientific Sessions \\ Orlando, FL, USA. 2-5 February 2012
}

\section{Background}

Abdominal aortic aneurysms (AAA) are a major cause of morbidity and mortality in the US. The most common location of AAA is the infrarenal abdominal aorta where oscillatory flow is present over the cardiac cycle, figure 1. Oscillatory flow is known to initiate an inflammatory response in endothelial cells.

Patients with lower extremity traumatic amputations have a 5 -fold increase in AAA occurrence unrelated to co-morbidities. The objective of the study is to determine the amount of infrarenal aortic oscillatory flow changes between baseline and acute occlusion of arterial blood supply to a lower extremity (a condition mimicking a lower extremity amputation).

\section{Methods}

Six healthy volunteers underwent MRI exam which included non-contrast MRA and PCMR measurement in the abdominal aorta. PCMR measurements were done at baseline and during 3-4 minutes of acute arterial occlusion using a blood pressure cuff to mimic a unilateral above knee (AKA) and bilateral above knee (Bi-AKA) amputation. PCMR scans were acquired perpendicular to the aorta at 2 levels: below the renal arteries and immediately above the aortic bifurcation. PCMR was used to create waveforms showing flow versus time over the cardiac cycle, figure 1 . In all subjects, we computed the percent of retrograde flow over the cardiac cycle at baseline and during the two acute occlusion conditions.

${ }^{1}$ Cardiology, Emory University School of Medicine, Atlanta, GA, USA

Full list of author information is available at the end of the article

\section{Results}

The retrograde flow was $17.9 \%+/-1.6$ at baseline. AKA resulted in a significant increase in retrograde flow above the aortic bifurcation, the most common site of AAA formation $(26.3 \%+/-4.2 \mathrm{p}<0.05)$. Bi-AKA further increased retrograde flow to $30.1 \%+/-3.9 \mathrm{p}<0.05$. Our results suggest that mimicking a traumatic amputation produces a significant increase in infrarenal retrograde aortic blood flow, leading to an increase in oscillatory wall shear stress, a precursor of endothelial dysfunction.

Additionally, the velocity profiles above the aortic bifurcation showed that during unilateral AKA, the diastolic reversal of blood flow was more pronounced on the side of the amputation. These findings agree with

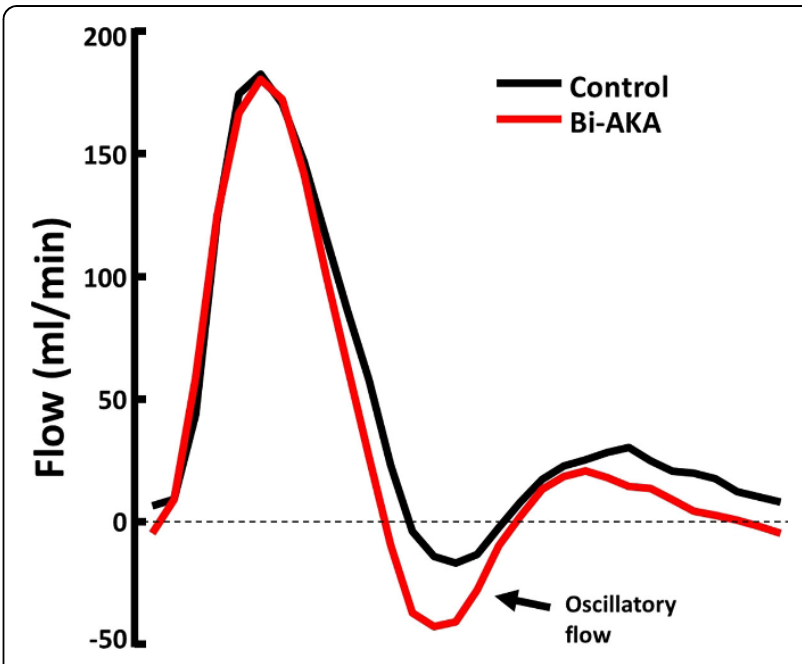

Figure 1

(c) 2012 Smolensky et al; licensee BioMed Central Ltd. This is an open access article distributed under the terms of the Creative 
clinical observations that amputees are at increased risk for AAA development and that these AAA tend to be asymmetric protruding toward the amputation side.

\section{Conclusions}

Traumatic lower extremity amputation increases retrograde flow in the infrarenal aorta. The mechanism for the increased risk of AAA development in amputees maybe augmentation of retrograde flow in the infrarenal aorta increasing the level of oscillatory wall shear stress.

\section{Author details}

${ }^{1}$ Cardiology, Emory University School of Medicine, Atlanta, GA, USA.

${ }^{2}$ Radiology, Emory University School of Medicine, Atlanta, GA, USA.

Published: 1 February 2012

doi:10.1186/1532-429X-14-S1-W12

Cite this article as: Smolensky et al:: Lower extremity amputation

increases oscillatory flow in the infrarenal aorta: A new potential risk

factor for abdominal aortic aneurysm development. Journal of

Cardiovascular Magnetic Resonance 2012 14(Suppl 1):W12.

Submit your next manuscript to BioMed Central and take full advantage of:

- Convenient online submission

- Thorough peer review

- No space constraints or color figure charges

- Immediate publication on acceptance

- Inclusion in PubMed, CAS, Scopus and Google Scholar

- Research which is freely available for redistribution

Submit your manuscript at www.biomedcentral.com/submit
C Biomed Central 